\title{
Vicente Huidobro: El Poeta contra su Doctrina
}

En la carrera del poeta chileno Vicente Huidobro el período netamente creacionista corre desde 1917, año en que publica sus primeros poemas creacionistas en la revista parisiense Nord-Sud, hasta 1925, fecha en que aparecen en París sus Manifestes, resumen y defensa de la doctrina creacionista, y las dos últimas colecciones de versos creacionistas, Automne régulier y Tout à coup. ${ }^{1}$ Durante estos años Huidobro propone en sus escritos teóricos una poesía autónoma, libre de elementos narrativos y descriptivos. Es un programa que va en contra del concepto romántico de la función de la poesia y del poeta que había enunciado Huidobro en Chile antes de pasar a Europa en 1916. El frío esteticismo de sus compañeros cubistas de Nord-Sud no satisface los deseos del poeta, reprimidos a medias durante los años aludidos, de hacer poesía profética y mágica. ${ }^{2}$ A partir de 1925 estos deseos hacen erupción en un tipo de poesía que viola los tabús cubistas y creacionistas, sobre todo en el poema Altazor. En este artículo quiero hacer ver cómo este cambio efectuado después de 1925 se anuncia ya en la poesía publicada por Huidobro du. rante el período creacionista.

Huidobro se hizo notar en 1917 y 1918 con seis libros de poesía publicados en París y en Madrid. En tres de estos libros, Horizon carré, El espejo de agua y Poemas árticos, se aproxima al ideal de los poetas de Nord-Sud, el de crear un mundo poético paralelo al mundo objetivo

1 Para los libros de Huidobro citados en este artículo véase la bibliografia.

2 Trato este punto en mi estudio "Perspectiva europea del creacionismo", Revista Iberoamericana, XXVI, Núm. 51, págs. 127-136. 
pero independiente de él. Estos poemas no alcanzan la meta de desterrar lo "anecdótico" porque la emoción que proyecta el poeta dentro de su mundo "creado" es de índole tradicional; son las quejas que vienen expresando los poetas líricos desde el comienzo del mundo. Representan, sin embargo, un esfuerzo por cumplir con un ideal imposible de realizar sin acudir a una poesía hecha sin palabras reconocibles. ${ }^{3}$

Pero durante estos años Huidobro vacilaba entre el estilo Nord-Sud, cuyos poetas negaban que el poema pudiera tener referencias extra-literarias, y la poesía del "esprit nouveau" de Guillaume Apollinaire y Blaise Cendrars, poesía que tenía un propósito francamente descriptivo y profético y que por lo tanto satisfacia mejor que el estilo Nord-Sud el romanticismo latente del poeta chileno. En tres libros publicados en 1918 Huidobro viola a sabiendas la prohibición que se había impuesto en la nota preliminar de su Horizon carré contra lo "anecdótico y descriptivo."

El primero de éstos es Tour Eiffel, poema descriptivo a la manera de la pintura simultaneísta, ilustrado con reproducciones de cuadros del pintor simultaneísta Robert Delaunay. Los cuadros en que Delaunay ensaya repetidas veces una síntesis visual de la torre habían inspirado el poema "Tour" de Blaise Cendrars. En "Tour" Cendrars evoca la torre en una serie de imágenes calidoscópicas que parecen haber servido en parte de modelo para el poema de Huidobro, en que la torre es guitarra, rosal, telescopio, clarín, "reine de l'aube des poles," "une araignée aux pattes en fil de fer," "la rose des vents qui se fane tous les automnes," "volière du monde," "sonnerie de París." En Tour Eiffel las imágenes y la disposición tipográfica son las del estilo Nord-Sud. Pero se emplean para describir un objeto real en el contexto de la primera guerra mundial. La torre, con su radiodifusora, es la portavoz profética de la Francia aguerrida: "Le géant pendu au milieu du vide/ Est l'affiche de la France/ Le jour de la Victoire/ Tu la racconteras aux étoiles."

El tema del día de la victoria vuelve a figurar en Hallali, "poème de guerre" en que otra vez el estilo Nord-Sud se emplea para crear una visión sintética de un tema no inventado. La palabra ballali representa el clarín de la guerra que se hace sentir a través de un continente:

3 Resumo en este párrafo mi estudio inédito "Vicente Huidoro: el estilo Nord-Sud."

4 El poema de Cendrars, que lleva la fecha de agosto de 1913, salió en 19 poèmes élastiques (París, 1919). 
1914

Nuages sur le jet d'eau d'été

La nuit

Toutes les tours de l'Europe se parlaient en secret

Tout d'un coup un oeil s'ouvre

La corne de la lune crie

Hallali

Les tours sont des clarions pendus

AOUT 1914

C'est la vendage des frontières

El "algo" misterioso que flotaba como amenaza velada al margen de los poemas de Nord-Sud toma aquí la forma concreta del cataclismo de la guerra: "Derrière l'horizon il se passe quelque chose/ Au gibet de l'aurore toutes les villes sont pendus." Las imágenes típicas del estilo Nord-Sud no se aplican en Hallali a objetos "creados":

Soldats vêtus de nuages bleus

Le ciel vielli entre les mains

Et la chanson dans la tranchée

Les trains s'en vont sur des cordes parallèles

On pleure dans toutes les gares

Le premier tué a été un poète

On a vu un oiseau s'échapper de sa blessure

Hallali, poema descriptivo y profético, termina con una visión del dia de la victoria que recuerda la de un poema de Blaise Cendrars, $L a$ Guerre au Luxembourg. ${ }^{5}$ En el poema de Cendrars:

A PARIS

Le jour de la victoire quand les soldats reviendront...

Tout le monde voudra LES voir

5 (París, 1916). 
Le soleil ouvrira de bonne heure comme un marchand de nougat un jour de fête

Il fera printemps au Bois de Boulogne ou du côte de Meudon

Toutes les automobiles seront parfumées et les pauvres chevauz mangeront des fleurs.

En la visión de Huidobro:

Même les aveugles

Sortiront aux balcons

Et leurs fleurs tomberont aussi sur les têtes des soldats

Le cortège viendra des siècles plus lointains

La foule dansera dans les yeux des chevaux

Cendrars, pues, presenta el día de la victoria como un renacimiento de la alegría de la vida. Para otro maestro de Huidobro, Guillaume Apollinaire, este renacimiento debe extenderse también a la poesía, a la lengua misma. Escribe en "La Victoire": "O bouches l'homme est à la recherche d'un nouveau langage... On veux de nouveaux sons de nouveaux sons de nouveaux sons". La victoria verá cumplirse su profecía:

La victoire sera avant tout

De bien voir au loin

De tout voir

De près

Et que tout ait un nom nouveaú

Huidobro comparte este deseo de encontrar un lenguaje de poder adivinatorio y profético al escribir su Ecuatorial, poema más largo y más complejo que Hallali. Aquí la guerra es sólo un aspecto de la visión del poeta. La línea ecuatorial del título es un punto central del tiempo y del espacio. Desde su atalaya el poeta divisa el presente y el porvenir. El desastre actual de la guerra presagia un futuro cataclismo. La línea ecuatorial forma también la frontera entre la realidad y la fantasía personal. En las visiones sucesivas, evocadas con las imágenes y la disposición tipográfica del estilo Nord-Sud, alternan cuadros de desastres fantásticos, exploraciones "creadas" y recuerdos de cosas vistas. El poeta da a entender que los desastres descritos son profecías:

6 De Galligrammes (París, 1918). 
Los hombres de mañana

Vendrán a descifrar los jeroglíficos

Que dejamos ahora

Escritos al revés

Entre los hierros de la torre Eiffel

Guillaume Apollinaire había dicho que los poetas aprenderían el arte de la profecía, y que las realidades poéticas llegarían con el tiempo a ser verdades de la vida. ${ }^{7}$ Porque creía en la necesidad de un lenguaje de poder mágico, Apollinaire pide "sonidos nuevos" que vayan más allá de la poesía tradicional. Es evidente que en Ecuatorial Huidobro juega con la misma idea. Pero sus jeroglíficos no son otra cosa que las imágenes "creadas" que en otros libros presenta como independientes de cualquier realidad que no sea la del poema. Dice en su ensayo "El Creacionismo" que el poema creacionista "es algo que no puede existir en otra parte que en la cabeza del poeta; no es bello porque recuerde algo, no es bello porque evoque cosas que se han visto y que eran bellas, ni porque describa cosas bellas que tenemos la posibilidad de ver. Es bello en sí y no admite términos de comparación. No puede concebirse en otra parte que en el libro."8

Así en este manifiesto Huidobro renuncia a toda posibilidad de hacer la poesía profética que ensaya en Ecuatorial. Acaso por este conflicto Ecuatorial resulta indeciso y difuso, siendo en gran parte una serie de las mismas imágenes creadas cuya posible realidad extra-poética ha negado el poeta. Sin embargo, en el poema quiere que se acepten como visiones que anuncian, en el verso final, "El fin del universo".

Huidobro no cree en la realidad de sus metáforas, pero quiere hacer poesía que se refiera a realidades no literarias. Quizá por esto deja sin terminar en 1919 otra visión apocalíptica en el estilo de Ecuatorial, la versión primitiva del primer canto de su Altazor, poema en cuya versión final (1931) adopta otra solución para el problema de la metáfora. Durante el resto del período creacionista, indeciso ante el atascadero de la metáfora, Huidobro abandona sus tentativas de hacer poesía francamente profética, volviendo al parecer al puro esteticismo del estilo Nord-Sud.

7 Véanse Guillaume Apollinaire: "L'Esprit nouveau et les poètes," Mercure de France, décembre, 1918 (Núm. 491, tomo CXXX), pág. 393, y el poema "Les Collines," de Galligrammes.

8 Citado en Vicente Huidobro: Antología (Santiago, 1945), pág. 261. 
Los resultados poéticos de esta segunda etapa del período creacionista se encuentran, dejando aparte el libro inédito Salle 14, en Automne Régulier y Tout à coup. Salle 14, colección de caligramas expuestos como "poemas pintados" en 1922 en una galería parisiense, contiene un poema de Horizon carré. 9 Los demás, todos nuevos, anticipan los motivos típicos de Automne Régulier y Tout à coup. Estas tres colecciones contienen los poemas más resueltamente creacionistas de toda la producción de Huidobro. Comparados con los de Horizon carré y Poemas árticos, estos poemas son notables por su abandono progresivo del ritmo entrecortado y de la disposición tipográfica del estilo Nord-Sud. Sobre todo a partir de $A u$ tomne régulier Huidobro se encamina hacia el ritmo de los metros tradicionales. A este efecto contribuye el empleo habitual de la rima, de una cadencia regular, de un verso más largo, y de una aproximación de la estrofa tradicional que sustituye poco a poco a los versos aislados del cstilo Nord-Sud. En cambio Huidobro sigue empleando muchas de las imágenes típicas de los libros anteriores. Pero estos poemas nuevos son más arbitrarios y en apariencia menos apegados a la realidad que los de Poemas árticos. Se distinguen asimismo por un tono más ligero y juguetón, gracias en parte al empleo casi sarcástico de la rima arbitraria, que a veces parece dictar el curso de poemas de ritmo irónico. 'Todo esto subraya la naturaleza arbitraria del paisaje que el poeta inventa a cada paso. En " 6 - Heures octobre", de Salle 14:

L'automne effeuille son calendrier

Et mon soleil s'éteint dans l'eau de mer

La mer la mer devient cendrier

La ciel devient un reverbère

C'est l'heure

$\mathrm{Du}$ violon de fleur

Pero por estas construcciones arbitrarias, con sus variaciones "creadas" del motivo del pasar del tiempo y de las estaciones, se insinúa la misma melancolía que había animado los poemas de Horizon carré y de

9 El poema de Horizon carré es "Paysage." Uno de los poemas nuevos. "Moulin," se publicó en la Antología de 1945. Copias de todos los poemas de Salle 14 existen en la colección de Gerardo Diego en Madrid. 
Poemas árticos. Este "dolor de poesía", de la imposibilidad de fijar en el canto los valores fugitivos, que se adivina entre las piruetas de Salle 14, se vuelve más agudo en Automne régulier y en Tout à coup. Los dos libros revelan un apetito cada vez más insaciable por lo maravilloso, por el infinito, por romper con las limitaciones del tiempo, del espacio, y de la estética que se había impuesto el poeta.

En Automne régulier predomina la melancolía del tiempo. El drama mudo de las estaciones forma el tema principal. El poeta es espectador pasivo y no el "pequeño dios" que quisiera ser. Hay que aceptar, dice en el poema titular de la colección, las pérdidas inevitables:

En vain tu cherches

Arbre d'Automne

Il n'y a plus d'oiseaux

Il n'y a plus d'oiseaux

En regardant sur les vallées

On voit partout des sons de cloches fanés

Le jour est plein mes mains aussi

A l'autre bout s'en sont allés

Le pas sans bruit

C'EST L'AUTOMNE DES CLOCHERS

Como en libros anteriores, el dolor de poesía se asocia aquí con el motivo del pájaro. En "Hiver à boire" dice más directamente: "Hirondelles de ma poitrine comme vous faites mal." Por inevitable que sea, el pasar del tiempo es doloroso. En "Eté en sourdine":

Le ciel

Le ciel

ma bergerie

Je crie à la bergère

Rentre ton troupeau de lits d'hôpital

Il est bien tard dans ton pays natal

Mes jours s'en vont

Ferme à clef l'horizon

Pero no hay nada que hacer. Como dice Huidobro en "Relativité du printemps", "On ne peut rien faire contre le soir qui naît." Según la 
estética creacionista el poeta no ha de lamentar; debe crear algo a base de las pérdidas ejemplificadas en la del tiempo. "Poème" comienza con el verso significativo "Colonise la douleur avec ta voix". El dolor a que se refiere es en parte el dolor del dilema que había encontrado en Ecuatorial, dolor de no haber dado con un lenguaje mágico como el que preconizaba Apollinaire en "La Victorie". La presencia de Apollinaire, cuya muerte es el tema del bello "Poème funéraire", se hace sentir en varios poemas de Automne régulier. En "Ombres chinoises" el motivo principal, la necesidad de que aprendan a cantar los aviones, "comme des flûtes tournées vers l'avenir", antes de morir--pues pronto serán viejos y olvidados-es una "verdad literaria" típica de las que presenta Apollinaire cn su artículo "L'Esprit nouveau et les poètes". ${ }^{10}$ El poema termina con una referencia directa a "La Victoire", la constatación melancólica de que "Il n'y a plus de nouveaux sons", confesión del dilema de Ecuatorial.

Huidobro expresa su reacción ante este dilema en "Poète":

Poète poète sans sortilege

Trois jours après le naufrage

Moulin moulin de neige

L'épaule est lourde de nuages

Vous êtes tous des robinets

Votre coeur saigne par le nez

Tais-toi rossignol au fond de la vie

Je suis le seul chanteur d'aujourd'hui

Je vous répète mille fois

Que mon épaule est lourde de nuages

Mais j'ai la flûte officielle du chérubin sauvage

El motivo del naufragio y de la persona ahogada aparece con frecuencia en la poesía de Huidobro. Es una de las formas del tema general del desastre visto o presentido que ocurre tanto en los poemas estrecha-

10 La más conocida de estas "verdades literarias" es ésta: si las mujeres se niegan a parir, lo harán los hombres, tema del drama de Apollinaire Les Mammelles de Tirésias, estrenado en París en 1917. 
mente creacionistas como en los de índole apocalíptica, como Ecuatorial, Altazor y Temblor de cielo, y que crea un lazo de unión entre los dos tipos de poesía. Va asociado de manera insistente con los valores fugitivos o perdidos y con el dolor de poesía, como en otros poemas de Automne régulier. (Sirvan de ejemplos el "océan verte de tant d'espoir noyé" de "La Matelotte", "la mer . . . chargée de naufrages" de "Poème funéraire", los versos de "Globe-trotter": "Dans cette mer ont fait naufrage/ Toutes mes barques fleuries", y estos del poema titular: "Au fond de mes yeux/ Chantera toujours le poète noyé"). En "Poète" el naufragio aludido es sin duda el dilema poético que vengo comentando; son decisivas las palabras "sans sortilège." El molino es, como en "Moulin", de Salle 14 y en Altazor, símbolo del tiempo inexorable. Así en "Poète", Huidobro, deseoso de escribir en un lenguaje mágico que no encuentra, prisionero del tiempo que corre, afirma el valor de su doctrina y se niega a lamentar, a abandonar el arte objetivo. Cantará a pesar de sus cuidados. $\mathrm{Y}$ en "Poème", la composición poética es un esfuerzo consciente ("le voyage sans rêve") por encontrar "les mots qui pendent au ciel."11

La tensión entre los deseos antagónicos de Huidobro se expresa en alto grado en los poemas numerados de Tout à coup. Aquí, como en Salle $14 \mathrm{y}$ en Automne régulier, el poeta explora un mundo que inventa a cada paso. En "3":

Je m'éloigne en silence comme un ruban de soie

Promeneur de ruisseaux

Tous les jours je me noie

Au milieu des plantations de prières

Les cathédrales de ma tendresse chantent

La nuit sous l'eau

Et ces chants font les îles de la mer

Cicerone frívolo de su universo improvisado, efectúa sus creaciones por medio del ojo todopoderoso. ${ }^{12}$ Viaja en " 18 " en "le bateau de l'oeil", y en " 11 " es por el ojo que ejerce su poder sobre el tiempo:

11 En Manifestes, publicado como este poema en 1925, Huidobro dedica varias páginas a un ataque contra las doctrinas de los superrealistas. Defiende su concepto de la poesia como producto del esfuerzo consciente y no del inconsciente (págs. 8-12).

12 En Manifestes (pág. 12) sitúa la creación poética en el momento en que la mirada del poeta se abre "démesurément jusqu'à remplir l'univers et l'absorber comme une pompe." 
Je suis un peu lune et commis voyageur

J'ai la spécialité de trouver les heures

Qui ont perdu leur montre

Croyez-moi bien

Sur mon oeil d'amiral tout se rencontre

Et ce n'est pas plus rare que les cas d'enfants

Perdus dans les magasins

Adopta un tono de seudopedantería, parodia del rigor de un estilo discursivo (" 1 " comienza: "Les deux ou trois charmes des escaliers du/ hasard sont incontestables"), y en la seudofrivolidad de los salones "creados" de "9" y de "30" el poeta hace eco de la ironía romántica de un Laforgue. La vida es un juego de salón que no encubre el tedio de los convidados. Estos poemas traducen en alto grado una añoranza de lo maravilloso, del infinito, de lo otro. En "28" Huidobro llama a sus juegos "des petites distractions pour linfini." Quisiera encontrar una realidad más allá de la de todos los días, diciendo en "5": "Il y a trop de choses/ Qu'on n'a pas vues". Estas "cosas que no se han visto" aparecen en "10", otra vez en términos irónicos:

Monte jusqu'au dernier étage

Alors elle pourra dire à mes amis

Connais-tu le pays

Je connais le pays

Elle pourra dire à mes amis

Messieurs la lune se décolle

J'ai compté toutes les monaies de l'infini

La rose qui manque au pôle

\section{$\mathrm{La}$ voici}

Le roe su apetito por lo maravilloso; alude a sus deseos en estos versos juguetones de " 6 ": "Je n'ai pas de chapeau/ Et pas d'ombrelle/ J'attends toujours une auréole fidèle". En "18", más directamente: "Rien dans la vie/ Qu'un cri d'antichambre". Anhela escaparse de este destino: "Le destin est un ruisseau/ Qu'il faut sauter au bon moment". Pero ¿cuál es el momento? El destino es tan fuerte que ni Dios puede contra él, como en " 20 ": 
J'aime regarder

Cette eau mélancolique comme les yeux de

Dieu

Qui ne peut pas ressusciter

Il voudrait descendre les marches de la nuit

Tel que les sons de cloche descendent la pluie

Mais il est arrêté par les syncopes

Des destins précis

Si Dios mismo es impotente, el "hombre-Dios" que es el poeta creacionista se siente doblemente encarcelado. Cabe ver en el estilo creacionista una camisa de fuerza que le impide al poeta hacer lo que más quiere y dentro de la cual lucha por libertarse. Indicios de la lucha son ciertos cambios técnicos que aparecen en la trayectoria poética que va desde Salle 14 hasta Tout à coup. El estilo paralelístico que empieza en "Moulin", de Salle 14 y en poemas como "Hiver à boire," de Automne régulier ("Tombe/ Neige à goût d' univers/ Tombe/ Neige qui sent la haute mer"), apunta a las letanías de Altazor, tan distintas por su forma y por su propósito del estilo Nord-Sud. Y las variaciones puramente auditivas de algunas palabras en Tout à coup (En "6": "Cinq papillons s'envolent en disant ces prières/ Aimez-vous les prières dans la prairie") anuncian otra técnica característica de Altazor y opuesta a las del estilo Nord-Sud, las deformaciones y disecciones de palabras que señalan el momento en que Huidobro encuentra inútil el estilo creacionista como fuente de los "sonidos nuevos" que buscaba.

En Tout à coup Huidobro logra crear el reino de la palabra virgen, la palabra "recién nacida" que tiene el efecto, mencionado en su discurso "La Poesía", leido en el Ateneo de Madrid en 1921, de "elevar al lector del plano habitual y envolverlo en una atmósfera encantada."13 Pero como afirma Huidobro una y otra vez en Manifestes, publicado como Tout à coup en 1925, se trata de una magia puramente verbal que no tiene otra realidad. Los productos del delirio poético, verdaderos en el poema, son falsos en la vida (pág. 14). Huidobro no cree, como los místicos, que sus imágenes puedan ser revelaciones del más allá, ni como Guillaume Apollinaire, que sus "verdades literarias" puedan llegar a ser verdades de la vida; por fin, no comparte el misticismo materialista de los super-

13 Citado en Antología, pág. 247. 
realistas ("Le surréalisme repose sur croyance à la réalité supérieure de certaines formes d'association negligées jusqu'à lui...).14

La doctrina creacionista de Huidobro le prohibe ver en sus manipulaciones otra cosa que el resultado del placer puramente estético de jugar con las palabras, "la seule chose qui passionne le poète," "le moment unique qui me fait oublier la réalité quotidienne." $15 \mathrm{Al}$ ponerse del lado de los poetas puros Huidobro niega las ambiciones y apetitos tan evidentes en una poesía cuya belleza autónoma encuentra cada vez más insuficiente.

University of California, Santa Barbara,

\section{DAVID BARY}

Goleta, California.

Libros de Vicente Huidobro citados en este texto

Horizon carré, Paris, 1917.

El Espejo de agua ("segunda edición,") Madrid, 1918.

Poemas árticos, Madrid, 1918.

Tour Eiffel, Madrid, 1918.

Hallali, Madrid, 1918.

Ecuatorial, Madrid, 1918.

Automne régulier, Patis, 1925.

Tout à coup, Paris, 1925.

Manifestes, Paris, 1925.

Altazor, Madrid, 1931.

Temblor de cielo, poema en prosa, Madrid, 1931.

Antologia, prólogo, selección, traducción y notas de Eduardo Anguita, Santiago, 1945.

14 Les Manifestes du surréalisme (París, 1946), pág. 45.

15 Manifestes, pág. 12. 